\title{
Transition to hospital process orientation: The case of regional hospitals in Latvia
}

\author{
Juris Barzdins*1, Rita Konstante ${ }^{2}$, Uldis Mitenbergs ${ }^{3}$, Maris Taube $^{3}$ \\ ${ }^{1}$ Centre for Health Management and Informatics, Faculty of Medicine, University of Latvia, Latvia \\ ${ }^{2}$ Norwegian hospital construction agency, Norway \\ ${ }^{3}$ Riga Stradins University, Latvia
}

Received: August 6, 2015

Accepted: November 26, $2015 \quad$ Online Published: December 14, 2015

DOI: $10.5430 /$ jha.v5n2p15

URL: http://dx.doi.org/10.5430/jha.v5n2p15

\begin{abstract}
Management of processes instead of functions has growing importance into the health care. Transition to hospital process orientation (HPO) changes the way physicians and other health professionals have used to practice before. Study was performed to explore factors affecting introduction of HPO in Latvian hospitals responding to significant external pressures during the years of economic crisis to detect the best practices used for process management implementation in clinical setting. To reach the research goal dissimilarities between current performance and management of hospitals were explored. As changes in hospital reimbursement system demand improved efficiency, hospital's performance was measured by decrease in avoidable hospitalisations, and increase in usage of more cost effective alternatives to a full hospitalisation. A regression analysis was performed to evaluate correlations of hospitalisation rates in Latvian hospitals to various outpatient health services utilisation indicators. This was done to exclude influence of external factors on hospital performance and to prove the positive impact of HPO initiatives on hospitalisation rate. Afterward the performance of all regional hospitals was compared and the two most distinct hospitals were selected for further in depth analysis. Operational data of the selected hospitals and a set of structured interviews outlined the differences between both hospital's managerial practices and factors affecting the introduction of process oriented initiatives. The theoretical research together with comparative analysis of approaches used in both hospitals served as a basis for elaboration of recommendations towards development of HPO and facilitation of the development of self-management competence of health professionals.
\end{abstract}

Key Words: Hospital, Process orientation, Socio-technical systems, General competence, Self-management

\section{INTRODUCTION}

Management of processes instead of functions together with adaptation of management principles and techniques that originate from the manufacturing and service industries has growing importance into hospitals around the world. ${ }^{[1-4]}$ With the rise of information technologies already decades ago various types of organisations started to look for efficiency as well as quality of service in processes instead of functional and hierarchical structures. ${ }^{[5]}$
Possibility of management of processes instead of functions in clinical setting is relatively new and is related to electronic recording of most patient related activities in hospital information systems. ${ }^{[6]}$ Introducing the term "hospital process orientation (HPO)", Gemmel et al. concludes, that the changing external environment and constant trend of further fragmentation of medical specialties has demonstrated that successful operation of a hospital more than ever depends on its ability to control processes rather than managing just in context

\footnotetext{
*Correspondence: Juris Barzdins; Email: juris.barzdins@lu.lv; Address: Centre for Health Management and Informatics, Faculty of Medicine, University of Latvia, Latvia.
} 
of functions and departments. ${ }^{[7]}$ Therefore the traditional functional structure of hospitals will have to be replaced by a structure which takes a holistic and systematic view on healthcare delivery as a service business process ${ }^{[8]}$ and traditional health delivery processes will have to be restructured into integrated care trajectories for nominated patient groups, which are manageable, measurable, and therefore accountable. ${ }^{[4,9]}$ However, there are no straightforward answers on how the transition to process orientation should be encouraged.$^{[7,10,11]}$ Introduction of HPO elements for adapting to the changing environment pose an unsolved problem there does not exist a conceptual framework that facilitates the transition of hospitals as open complex socio-technical systems to process oriented management.

Hospitals in Latvia could serve as an example of rapid and worth of deeper exploration changes, including transition to process orientation, triggered by extreme pressure to reduce costs and optimize utilisation of existing resources. In a period of recent economic crisis, after years of significant growth, Latvian economy at the end of 2008 collapsed with more than 20\% (in local currency) drop in Gross Domestic Product (GDP) during 2009 and 2010. and rather slow recovery later on - in 2013 GDP was mere $1.8 \%$ higher than that in 2008. ${ }^{[12]}$ Accordingly to WHO Global Health Expenditure Database, ${ }^{[13]}$ government expenditure in Latvia for health care dropped from $4.1 \%$ of GDP in 2008 (then second lowest in EU) to $3.5 \%$ in $2013(-14.2 \%)$ and one of the highest in EU level of Out of Pocket Expenditure as percent of Total Health Expenditure (THE) increase from $33.7 \%$ in 2008 to $36.5 \%$ in 2013. However increased private spending did not compensate the drop in public spending and THE related to GDP dropped from $6.6 \%$ to $5.7 \%$ which was the highest relative drop in this period in EU countries (-13.8\%). Particularly the hospital sector was most affected by decrease in health care funding - the government expenditure on inpatient care as percent of general government health expenditure decreased from $40.1 \%$ in 2008 to $29.3 \%$ in $2013(-26.9 \%)$.

After the reforms in 1990s when a split of the purchasing and providing functions was introduced, hospital services were purchased by single authority, directly subordinated to the Ministry of Health. Until the beginning of the crisis, hospitals in general were paid according a per bed day tariff (price), fee-for-service payments for operations and diagnostic procedures and for certain conditions, case based payment was applied. ${ }^{[14]}$ Contracts with inpatient facilities were based on the rank of the hospital, such as university, regional multiprofile or local multi-profile. In addition, contracts included specified payment conditions defined by the annual cap on the budget accordingly to the estimated limit of hospitalisations. ${ }^{[15,16]}$ However, it was common, that most of the hospitals still treated larger number of patients or performed more expensive manipulations than it was stipulated in the contract referring to the fact that they cannot influence the objective rise in demand because of insufficient availability of outpatient services. ${ }^{[17]}$ As the budget cap per hospital for next year was calculated prospectively by multiplying the number of patients treated in the previous year (with certain adjustments) with a corresponding patient tariff, taking a risk for exceeding the budget for actual year was a kind of a guaranty for increased budget cap for each subsequent year. Mentioned situation was tolerated as growth of economy and allowed to increase financing of inpatient health care - five years before the crisis recession started, hospitals on average enjoyed $19 \%$ annual budget growth. ${ }^{[13]}$

However, since 2009, it was recognized, that calculated tariffs are not costs of services sold and depreciation of capital investments and that de-facto hospitals now were paid through limited global budgets. ${ }^{[18]}$ Together with the lost motivation of hospitals to induce more admissions and the need to stick to defined decreased budgets, alternative treatment options to hospitalization were promoted by further prioritising in budget redistribution to ambulatory, day, home and pre-admission observational care. Consequently, the number of hospitalisations sharply dropped by more than $21 \%$ during 2009. ${ }^{[19]}$

The described rather rapid changes in payment scheme and unprecedented financial pressures were the triggering factor for hospitals to introduce in hospital management methods from private sector and other industries in order to improve their efficiency, including a shift from a traditional functional focus on needs of particular medical specialisation, to a more process oriented focus on a needs of patients' groups with similar clinical process pattern caused by belonging to the same age, stage, complexity or urgency groups. The development of new forms of services could be regarded as a turning point for Latvian hospitals in the direction to process orientation, as the new services and structures were not anymore focused on functions among the staff involved in treatment, but oriented to the needs of the homogeneous patient group. Change in the direction of HPO is also seen in the structural changes with opening of new units based on the analysis of the needs of uniform patient groups (like observation, day care and low treatment intensity/nursing units).

However, the motivator for the mentioned process-oriented change primarily is the external stimulus demanding the cost effectiveness, not patient's as hospital's client's perspective. Although research shows that transition to process orientation besides reducing cost also lead to a more patient-centred care and quality improvements, ${ }^{[20,21]}$ in reality, according to a 
review of 86 studies on innovations related to re-engineering patient care, the dominant motivator for initiation of these changes was cost reduction and resource utilisation, while parameters related to patient experience and patient values were rarely used. ${ }^{[22]}$ Therefore, the Latvian case while being a rather extreme example of the forced change, is however typical regarding the main motivator behind it. Respectively, by exploring the differences in adaptation in Latvian hospitals exposed to the same external environmental changes, the best practices used for process management implementation in clinical setting could be detected and further applied in other hospitals moving towards HPO.

Elaboration of evidence based recommendations for introduction of process orientated approaches in hospitals is the main objective of the research presented in this paper. Along the investigation of the management system elements determining the differences in hospital physician performance, evaluation of the need for cultural and therefore sustainable change among clinicians as ultimate decision-makers in clinical processes was also conducted.

To review the elements of the management system, which determines the differences in hospital physicians' performance, initially the differences in the adaptation in various hospitals with similar external conditions were analysed. This analysis was needed to confirm or invalidate the above mentioned expressed opinion regarding impossibility of hospitals to influence hospitalisation rate. Assuming that higher hospitalisation rate could be related to insufficient availability/use of ambulatory care, formulated was first of the research questions: (1) Is there correlation between per capita hospitalisation ratios to the intensity of utilisation of non-hospital health care? Assuming that lower level of hospitalisations could be related to hospital initiated activities, formulated was the second research question: (2) Is there a correlation between per capita hospitalisations and the usage of process oriented hospital services? Having answered the first two questions, the third question was asked: (3) which two out of seven country's regional municipal hospitals differs the most according to the incidence of variables representing the level of the clinical process adaptation to external pressures. Finding out answers to these questions, it is possible to ask the main research question: "what are the differences between the professional activities of doctors and the management towards the clinical processes in hospitals where the result of clinical activities differ most?"

\section{RESEARCH MODEL AND METHODS}

The chosen research model is based on the use of method of mixed methods research, that gets increasingly wider application in the fields of sociology, psychology, education,

Published by Sciedu Press and health sciences. ${ }^{[23]}$ Although most of the empiric study consists of quantitative research, its parts are integrated in the qualitative research, using the case study method. The case study method is applied on the basis of the conclusion of its developer Yin ${ }^{[24]}$ that "the need for case studies arises out of the desire to understand complex social phenomena" as "the case study allows an investigator to retain the holistic and meaningful characteristics of real-life events".

In light of this, the conditions needed for introduction of process-oriented management in Latvian hospitals are studied using various data sources and the results of research carried out in several stages are analysed in the following sections:

Assessment of the impact of HPO initiatives in major regional hospitals in Latvia - using both quantitative and qualitative studies. The quantitative study included secondary data processing, statistical analysis and interpretation of the NHS data for quantity and costs of the inpatient and outpatient care that was provided by public services in all 118 municipalities for a population youngerolder than 65 years over one full year (2011). The data was analysed per capita of the specific age group by using Central Statistical Bureau 2011 population census data for the population size and age structure in each of the territories. ${ }^{[25]}$ The qualitative studies included simultaneously use of the various data sources, including organisational charts of hospitals, governmental regulations and hospitals' contracts in electronic archives of NHS, as well as interviews using open-ended questions. Assessment components were:

(1) Quantitative research with a goal to establish whether the inter-hospital variations of defined quality and efficiency indicators (hospitalisation and re-hospitalisation) could indicate the differences in management and professional activities of physicians:

- The determination of possible correlation between per capita hospitalisation and values indicating the usage intensity of ambulatory non-hospital health care services (outpatient specialists visits, outpatient diagnostics, visits to family doctor);

- The determination of possible correlation between per capita hospitalisation and values indicating the usage intensity of process oriented hospital services (treatment cases at Emergency medical assessment [EMA])

(2) Quantitative research with a goal to determine performance differences between Latvian hospitals and to select of the two most distinct hospitals for further in-depth opposite case study. Three largest university hospitals having unique tertiary care programs as well as specialised and small local 
hospitals (less than 250 beds) were excluded in this stage. Remaining seven regional general hospitals localised in largest cities in opposite to larger university hospitals and the small rural hospitals all have similar NHS contract conditions and therefore experience the same financial inducements aimed to promote engagement of hospitals in development of more cost effective services as an alternative to traditional hospital admissions. Four incidence variables (attributed to one resident of hospital area) were measured: 1) number of hospitalisations, 2) number of re-hospitalisations, 3) number of treatment cases in EMA department, and 4) day hospital unit. For the measuring the degree of reciprocal differences of a hospital, author uses the weighted product method (WPM): to obtain a non-dimensional value using WPM, the performance criteria of each specified product in a particular area is applied against the performance of each product. ${ }^{[26]}$ The summary rating of each hospital $(V)$ for all criteria together is calculated using the Equation 1:

$$
V=s_{1} \times v_{1}+s_{2} \times v_{2}+s_{3} \times v_{3}+s_{4} \times v_{4}
$$

Where attributed to a single resident of the population $s_{1}$ is the number of hospitalizations, $s_{2}$ is the number of rehospitalizations, $s_{3}$ is the number of treatments in EMA without consequent hospitalisation and $s_{4}$ is the number of patients at day-hospital unit, while the $v_{1}, v_{2}, v_{3}$ and $v_{4}$ are the rank of a particular hospital for each of criterion in relation with other hospitals, giving the first place in the rank to hospital in case of $v_{1}$ and $v_{2}$ to the hospital which have the lowest number of per capita hospitalisations and rehospitalisations and in case of $v_{3}$ and $v_{4}$ - the highest number of used alternatives to traditional hospitalisation (episodes of treatment EMA and day-hospital).

(3) The qualitative research of the paired-case for the identification of the barriers and the prerequisites for successful implementation of the process-oriented hospital management.
Structured interviews were carried out using a scheme based on theoretical research and practical findings in hospitals. The clarity and purposefulness of the interview questions were previously tested with two independent health care management experts. The interviews were designed so that their length does not exceed 45 minutes. Interviews were aimed to detect the maturity of the hospital management towards changes addressing the needs of homogeneous groups of patients. The interviews: 1) found sustainable development issues identified by hospital managers (in the context of the need to provide care for the specific target groups of patients); 2) identified the pattern of changes towards the adaptation of clinical processes to external changes (in circumstances where there was introduced a fixed payment for treatment cases); 3) found the level of integration of hospital clinical process with outpatient health and social care (in-hospital alternatives to traditional hospitalization, cooperation with the out-hospital institutions); and 4) identified and explained quality problems of clinical process (regarding rehospitalisation of patients and hospitalization of patients with conditions that could potentially be managed on out-patient basis). The transcripts of interviews were analysed and interpreted independently by two researchers accordingly to the guidelines from Giorgi. ${ }^{[27]}$

\section{RESULTS}

A simple regression analysis was performed with dependent variable "hospitalisations" and five independent variables representing the utilisation of non-hospital health care (external factors) and utilisation of process oriented hospital services (internal factors) and allowed to draw important an conclusion for further exploration - the differences in the frequency of hospitalizations in hospitals cannot be explained with the differences in the external environment of the hospital and the cause for different level of hospitalization and the demand for hospitalisation must be sought for by looking at the hospital's internal environment (see Table 1).

Table 1. Per capita correlations of hospitalisations to various external and internal factors in all administrative territories $(\mathrm{n}=118)$

\begin{tabular}{|c|c|c|c|c|c|}
\hline & \multicolumn{3}{|c|}{ External factors } & \multicolumn{2}{|c|}{ Internal factors } \\
\hline & $\begin{array}{l}\text { Outpatient } \\
\text { specialists visits }\end{array}$ & $\begin{array}{l}\text { Outpatient } \\
\text { diagnostics }\end{array}$ & $\begin{array}{l}\text { Visits to } \\
\text { family doctor }\end{array}$ & $\begin{array}{l}\text { Treatment cases at EMA unit } \\
\text { without hospitalisation }\end{array}$ & $\begin{array}{l}\text { Treatment case at } \\
\text { day hospital unit }\end{array}$ \\
\hline Level of significance & .195 & .269 & .651 & .180 & .000 \\
\hline
\end{tabular}

*.01 significance

There was no negative correlation/statistically significant correlation found between hospitalizations in acute care hospitals and any outpatient health care services. There was statistically significant negative correlation found between hospitalisations and such internal factor as treatment cases in day hospital unit. 
Further research demonstrated different results of manage- the hospitals indicate significant differences in the results ment efforts and physicians' professional activity in seven Latvian regional hospitals in respect to volume and activity profile. Different weighted values of the average rating of of clinical activities of hospitals and differences in usage of cost effective services as alternative to hospitalization (see Table 2).

Table 2. Summary result of management efforts and physicians' professional activity per capita in major Latvian cities and its ranking

\begin{tabular}{|c|c|c|c|c|c|c|c|c|c|}
\hline & \multicolumn{2}{|c|}{ Hospitalisations } & \multicolumn{2}{|c|}{ Re-hospitalisations } & \multicolumn{2}{|c|}{$\begin{array}{c}\text { Treatments at EMA } \\
\text { without hospitalisation }\end{array}$} & \multicolumn{2}{|c|}{$\begin{array}{c}\text { Treatment cases in } \\
\text { day-hospital }\end{array}$} & \multirow{2}{*}{$\begin{array}{l}\text { Summary } \\
\text { rating }\end{array}$} \\
\hline & Count & Rank & Count & Rank & Count & Rank & Count & Rank & \\
\hline Jelgava & 0.309 & 3 & 0.077 & 3 & 0.197 & 5 & 0.312 & 2 & 2.77 \\
\hline Ventspils & 0.316 & 4 & 0.093 & 6 & 0.213 & 4 & 0.187 & 6 & 3.80 \\
\hline$\underline{\text { Liepāja }}$ & 0.248 & 1 & 0.063 & 1 & 0.303 & 2 & 0.432 & 1 & $\underline{1.35}$ \\
\hline$\underline{\text { Daugavpils }}$ & 0.347 & 7 & 0.096 & 7 & 0.143 & 7 & 0.242 & 4 & $\underline{5.07}$ \\
\hline Valmiera & 0.284 & 2 & 0.076 & 2 & 0.317 & 1 & 0.216 & 5 & 2.12 \\
\hline Jēkabpils & 0.319 & 5.5 & 0.079 & 4 & 0.164 & 6 & 0.110 & 7 & 3.82 \\
\hline Rēzekne & 0.319 & 5.5 & 0.082 & 5 & 0.295 & 3 & 0.303 & 3 & 3.96 \\
\hline
\end{tabular}

The used method allows to identify that the most distinctive situation is in Daugavpils $(\mathrm{V}=5.07)$ and Liepaja $(\mathrm{V}=1.35)$ hospitals. Comparing additional data in NHS archive it was also confirmed that both acute care hospitals serving the cities are comparable - they provide similar number of specialized programs and there was no significant difference in intra-hospital mortality.

Further opposite cases study of two hospitals with most prominent differences in internal practices answered the main research question: "what are the differences between the professional activities of doctors and the management towards the clinical processes in hospitals where the result of clinical activities differ most?"

The analysis of structured interviews showed that managers in Liepaja, to a greater extent than in Daugavpils are ready to tackle the problems of specific groups of patients by facilitating improvements in the hospital. For example, the prevailing thinking in Daugavpils is represented by one of the interviewee's view regarding the care for the elderly after hospital discharge: "I evaluate it as unacceptable, [...], there is no system established for further care, family physicians must take responsibility the secondary care after hospitalization." The prevailing attitude in Liepaja is disagreeing with this opinion: "there is a problem and we have to handle the situation, we've adapted to it, the doctors and the nurses collaborate with the hospital's social worker to handle each situation individually to ensure those patients have some care after hospital." This highlights the differences in to the understanding of the general common needs (the elderly, who, in order to avoid re-hospitalisation after discharge need assistance for arranging further care at home) providing a dif- ferent vision for the implementation of organization's clients' needs.

Interviewees in both hospitals recognize that in the recent years, the duration of treatment of patients has decreased and as the main reason cited are changes in the system how hospitals are reimbursed for their services. Existing payment for bed-days and fee-for-service payment for manipulations carried out are changed to constant fee-for-case payments for patients who belong to certain groups of diagnosis regardless of treatment duration: "quota (to be completed) and the per-case payments stimulates discharge" (Daugavpils); "we have little interest in keeping patients if the necessary medical treatment is arranged" (Liepaja); "the higher the turnover of patients, the more money is left for the hospital" (Daugavpils).

Differences in responses were observed also when describing the efforts to reduce the treatment time. The decrease in duration in Daugavpils was attributed to "disproportionately high co-payments" (referring to situations when patients simply cannot afford the longer treatment) and reduction of treatment lengths was not associated to the possible implementation of new treatment methods. Instead of that, interviewees in Liepaja frequently pointed at the objective opportunities to reduce treatment time by reorganizing processes, intensifying and standardising diagnostic and treatment work, as well as using new alternatives to hospitalisation: "the process is organized, there are guidelines developed to show a set of activities to be implemented. It helps maintain the momentum. We try to free the bed for the next patient and for that we have developed a home care service - we can discharge quickly enough [...] we have introduced home care and try 
to use it as much as we can get it reimbursed. With information technologies we can check previous treatments and diagnostics to avoid unnecessary delays and expenditures."

Further analysis of transcripts of interviews allows to conclude that Liepaja hospital is already managed towards HPO and is adapted better to the changes in the external environment (introduced per-case payment, economic disadvantage for long hospital stays). Both hospitals have decreased the average length of stay. However, the orientation towards process and customer allows Liepaja to have a lower rate of the next day re-hospitalisations than Daugavpils (1.4\% vs. $1.0 \%)$ and a lower rate of the same year re-hospitalisations (9.6\% vs. 6.3\%) (see Table 2). This situation suggests that the duration of treatment in one of the hospitals is reduced more by administrative methods (possibly compromising the autonomy of the medical profession), while in the other hospital doctors are balancing their clinical decisions in the interests of the patient and the organisation. The fact that the interviewees in Daugavpils do not mention targeted efforts to adapt to new situation might suggest that the hospital's management is less orientated to process management and rely more on traditional functional management without setting common organisational goals. In turn it does not allow doctors to develop new general competences necessary for balancing individual and collective goals.

\section{Discussion}

Initial quantitative part of the performed research give defined answers to first two research questions. It confirms that there is no evidence supporting the statement that changes in hospitalisation rate and changes in availability of out-patient services are related (no negative correlation). It confirms that introduction of process oriented hospital services and decreased number of hospitalisations are related (existing positive correlation with significance for one of parameters). This is an important finding of practical value for supporting with local evidence further initiatives towards process orientation in Latvian hospitals. At the same time these findings are in line with those in United Kingdom and Germany having found no dependent pattern between hospitalisations and utilisation volumes of outpatient care per se - the objective need for hospitalisations is determined by rather complex impact of primary, social, emergency care and the way how vulnerable patients are discharged from hospitals and multidisciplinary process oriented units (like observational and day surgery units) decrease avoidable hospitalisations. ${ }^{[28,29]}$

The synthesis of the multiple results of this study, including mentioned examples by interviewees together with the full analysis of interview transcript allowed to identify the key obstacles and success factors towards HPO. One of the main findings emerging from this case study shows us the need for clinical leadership for transforming hospital processes. Transition to HPO changes the way physicians and other health professionals have used to practice before. Gemmel et al. have noted that "hospital employees were not used to thinking in terms of processes and lacked training to develop these skills" while HPO requires such skills.

Explored transition towards more process oriented management highlights a new social challenge for both managers and doctors. Achieved transparency and possibility to control clinical process with precise and comparable data increases the manager's ability to monitor clinical process, which doctors, having used to focus on the needs of individuals, often perceive it as growing managerial control on clinical process and as a threat to the autonomy of their profession. Both, introduction of management methods proved successful in other industries and increased abilities of managers direct influence on clinical process have already raised scientific interest in both medical and managerial fields in the last decades, the organization and professional relationships is an increasingly explored topic in the literature. ${ }^{[30]}$

Clinical leadership - ability and willingness of medical professionals to participate in the change, highlights the need for development of self-managing capabilities in doctors with both social and technological interventions. Performed research of the problems to be solved for transition to processoriented management while responding to external changes, highlights the need for development of new competencies for those working at hospital. This is a growing understanding noted also by other researchers concluding that changed circumstances increase the need for doctors who are able to balance the needs of individual patients, departments, organizations and society. ${ }^{[31]}$ as "the individual orientation that doctors were trained for does not fit with the demands of current healthcare systems". [32] Various authors have already mentioned the need for health professionals additionally to their professional competencies also to have general competence as doctors while performing their professional duties are controlling the key business process within the organisation and leading the teams. ${ }^{[33-35]}$

The comparative analysis of approaches used in the two most distinctive hospitals, together with the mentioned finding from other studies served as a basis for elaboration of the following recommendations towards development of HPO.

The first task is to take the necessary steps to guarantee the rise of awareness regarding recognition of patient needs as the needs of organization's customer. Without progress in this direction, further development of process-oriented management is not possible. Orientation of the organization 
towards patient as a customer must become an integral part of the daily communication at the hospital at all levels. This task could be considered fulfilled if there is a collective commitment to focus primarily on customer needs, and therefore, continuously improve the clinical and care processes in the hospital.

The second task is to ensure that there is a collective understanding of the clinical process as a whole sequence of patient contact with staff and related set of activities starting from the moment, when there is a need to seek treatment in the hospital until the hospital treatment is no longer required. A method for achieving this task is creating a modelling process and analysis of required resources for detected uniform patient flows as well as defining the indicators of effectiveness and quality measurement for each particular process.

The third task is to increase the significance of the processoriented view in the management of hospitals. To strengthen the process-orientation as an important dimension of managing an organization that maintains a functional structure, the hospital's senior management has to actively promote the mentality of process orientation and systemic approach for improvements. It is important to support both informal and formal leadership, and to authorize teams, which have assumed responsibility for the improvement of particular processes.

The fourth task is to increase the significance of the processoriented view in the clinical domain of a hospital. This task largely echoes the first task - the ability and motivation to regard patient as a customer of the organization and to behold all the activities associated with their treatment and care as a single and primary process for the organisation. Encouraged should be the ability for co-workers when it is necessary to take horizontal responsibility, which crosses functional borders. Therefore, it is important that the highest possible number of hospital employees have an experience in process improvement by analysing and modelling the change and have developed a general competence due to the integration of relevant courses in professional education of health care professionals.

The fifth task is socio-technical - it requires the shift in the mind-set of managers and medical professionals, and simultaneously it requires a technological approach for granting access to process-oriented knowledge not only to managers, but also to doctors and other professionals in the hospital. The social component of this assignment is related to the competencies, including knowledge, skills and motivation of the staff involved in the clinical process most importantly of the doctors who determine the course of this process. The technological component of this exercise is associated with the transformation of data accumulated in clinical process into the new process-oriented knowledge for those involved in it along with the development of self-management skills.

To enable the introduction of process-oriented hospital management, the set of defined consecutive tasks of the presented methodology should be implemented with the central idea to optimize patient flow across the borders of existing functional structures. Taking into account that process management is underlying a permanent change and elaborated recommendations are based on a snap-shot of the situation at the time of the analysis a PDCA (plan-do-check-act cycle) approach should be used in both management of changes in hospital processes and in methodology used for facilitation of HPO.

\section{Conclusion}

The transition of hospitals towards process orientation and patient care across professional and functional organisational boundaries is a long term transformational process. Conducted analysis of performance and management of Latvian hospitals provides evidence for facilitation of further initiatives towards HPO. In case of a process-oriented management the role of hospital's physicians' changes and selfmanagement based on good process knowledge becomes even more important for sustainability of the hospital. The development of physicians' general competence should also be supported by invention and introduction of IT based tools allowing clinicians to see and control their individual work in systemic perspective.

The presented research is limited by being more focused on aspects of organisation-professional interaction during a change. It leaves place for further research regarding the selection of indicators that measure the process components and it's effectiveness including not only volume and financial indicators, but also indicators for the level of patient satisfaction, clinical outcomes, waiting time, process time, consumption of various resources, activities of individuals and teams.

\section{REFERENCES}

[1] Hellström A, Lifvergren S, Quist J. Process management in healthcare: investigating why it's easier said than done. J Manuf Technol Manag. 2010; 21(4): 499-511. http://dx.doi.org/10.1108/1

\section{7}

[2] Langabeer JR, DelliFraine JL, Heineke J, et al. Implementation of Lean and Six Sigma quality initiatives in hospitals: A goal theoretic perspective. Oper Manag Res. 2009; 2(1): 13-27. PMid: 15358969. 
http://dx.doi.org/10.1007/s12063-009-0021-7

[3] Bazzoli GJ, Dynan L, Burns LR, et al. Two Decades of Organizational Change in Health Care: What Have we Learned? Med Care Res Rev. 2004; 61(3): 247-331. PMid: 15358969. http: //dx.doi.org/10.1177/1077558704266818

[4] Gonçalves PD, Hagenbeek ML, Vissers JMH. Hospital process orientation from an operations management perspective: development of a measurement tool and practical testing in three ophthalmic practices. BMC Health Serv Res. 2013; 13: 475. PMid: 24219362. http://dx.doi.org/10.1186/1472-6963-13-475

[5] Davenport T, Short J. The New Industrial Engineering: Information Technology And Business Process Redesign. Sloan Manage Rev. 1990; 11-27.

[6] Berg M. Patient care information systems and health care work: a sociotechnical approach. Int J Med Inform. 1999; 55(2): 87-101. http://dx.doi .org/10.1016/S1386-5056(99)00011-8

[7] Gemmel P, Vandaele D, Tambeur W. Hospital Process Orientation (HPO): The development of a measurement tool. Total Qual Manag Bus Excell. 2008; 19(11): 1207-17. http://dx.doi.org/10.10 $80 / 14783360802351488$

[8] Parnaby J, Towill DR. Enabling innovation in health-care delivery. Health Serv Manage Res. 2008; 21(3): 141-54. PMid: 18647942. http://dx.doi.org/10.1258/hsmr.2007.007014

[9] Ain AK, Thompson JM, Kelley SM, et al. Fundamentals of service lines and the necessity of physician leaders. Surg Innov. 2006; 13(2): 136-44. PMid: 17012155. http://dx.doi.org/10.1177/15533 50606291044

[10] Jonas S, Goldsteen TL, Goldsteen K. An Introduction to the US Health Care System. Sixth Edit. Springer Publishing Company; 2007.

[11] Vos L, Chalmers SE, Dückers M La, et al. Towards an organisationwide process-oriented organisation of care: A literature review. Implement Sci. 2011; 6(1): 8. PMid: 21247491. http://dx.doi.org /10.1186/1748-5908-6-8

[12] Central Statistical Bureau of Latvia. Gross Domestic Product - Database [Internet]. 2015 [cited 2015 Nov 5]. Available from: http://www.csb.gov.lv/en/statistikas-temas/gro ss-domestic-product-database-30518.html

[13] WHO. Global Health Expenditure Database [Internet]. 2015 [cited 2015 Nov 5]. Available from: http://apps.who.int/nha/dat abase/Home/Index/en

[14] Tragakes E, Brigis G, Karaskevica J, et al. Health Systems in Transition 2008. Latv Heal Syst Rev. 2008; 10(2): 1-276.

[15] Regulations on organization and financing of health care. Regulations of the Cabinet of Ministers. Government of Latvia; 2006.

[16] Mitenbergs U, Taube M, Misins J, et al. Latvia: Health system review [Internet]. In: Health Systems in Transition. The European Observatory on Health Systems and Policies; 2012. page 191. Available from: http://www.euro.who.int/_data/assets/p df_file/0006/186072/e96822.pdf

[17] LETA news agency. The quota overdraft is limiting hospital health care (In Latvian). 2008 [cited 2015 Oct 7]. Available from: http: // leta.lv/archive/search/?patern=slimn\%C4\%ABca+kvota s\&item=7DB9C9EE-88FD-4F43-B294-586ADCB40337\&date= $1199138400 \% 2 \mathrm{C} 1262296800 \&$ mode $=$ stem $\% 2 \mathrm{Cwide} \% 2 \mathrm{C} \& \mathrm{print}$

[18] State Audit Office. Report on legality and economics of consumption of state budget funds by reimbursing health services in accordance with the set tariff. 2011.

[19] Ministry of Health. Information report "On the situation in the health sector" [Internet]. 2010 [cited 2015 Oct 7]. Available from: http://www.vm.gov.lv/images/userfiles/phoebe/ties ibu_akti_informativie_zinojumi_bda100dbcea27d1dc22 576f800338630/vmzino_140610.docx

[20] Kohlbacher M. The effects of process orientation: a literature review. Bus Process Manag J. 2010; 16(1): 135-52. http://dx.doi.org /10.1108/14637151011017985

[21] Vera A, Kuntz L. Process-based organization design and hospital efficiency. Health Care Manage Rev. 2007; 32(1): 55-65. PMid: 17245203. http://dx.doi.org/10.1097/00004010-2007010 00-00008

[22] Elkhuizen SG, Limburg M, Bakker PJM, et al. Evidence-based reengineering: re-engineering the evidence. Int J Health Care Qual Assur. 2006; 19(6): 477-99. http://dx.doi.org/10.1108/095 26860610686980

[23] Teddlie C, Tashakkori A. Major Issues and Controversies in the Use of Mixed Methods in the Social and Behavioural Sciences. In: Tashakkori A, Teddlie C, editors. Handbook of Mixed Methods in Social \& Behavioral Research. Thousand Oaks: Sage; 2003. 3-50.

[24] Yin RK. Case study research, design and methods. Thousand Oaks: Sage; 2003.

[25] Central Statistical Bureau of Latvia. Population Census 2011 - Key Indicators. 2011 [cited 2015 Oct 4]. Available from: http://www.csb.gov.lv/en/statistikas-temas/populat ion-census-2011-key-indicators-33613.html

[26] Triantaphyllou E. Multi-criteria decision making methods: a comparative study. Dordrecht: Kluwer Academic Publishers; 2000. PMid: 10944406. http://dx.doi.org/10.1007/978-1-475 7-3157-6

[27] Giorgi A. The theory, practice, and evaluation of the phenomenological method as a qualitative research procedure. J Phenomenol Psychol. 1997; 28: 235-61. http://dx.doi.org/10.1163/156 916297X00103

[28] Purdy S. Avoiding hospital admissions. 2010. Available from: http: //www.kingsfund.org.uk/sites/files/kf/Avoiding-Hos pital-Admissions-Sarah-Purdy-December2010.pdf

[29] Burgdorf F, Sundmacher L. Potentially avoidable hospital admissions in Germany. Dtsch Arztebl Int. 2014; 111(13): 215-23. PMid: 24739884. Available from: http: //www. pubmedcentral.nih.gov/articlerender.fcgi?art id=3991158\&tool=pmcentrez\&rendertype=abstract

[30] Von Knorring M, de Rijk A, Alexanderson K. Managers' perceptions of the manager role in relation to physicians: a qualitative interview study of the top managers in Swedish healthcare. BMC Health Serv Res. 2010; 10: 271. PMid: 20849581. http://dx.doi.org/10.1186/1472-6963-10-271

[31] McConnell CR. The health care professional as a manager: balancing two important roles. Health Care Manag (Frederick). 2008; 27(3): 277-84. http://dx.doi.org/10.1097/01.hcm.000031 8759.21654.d2

[32] Edwards N, Kornacki MJ, Silversin J. Unhappy doctors: what are the causes and what can be done? BMJ. 2002; 324(7341): 835-8. PMid: 11934779. http://dx.doi.org/10.1136/bmj . 324.7341 .835

[33] Burns LR, Bradley EH, Weiner BJ, et al. Shortell and Kaluzny's Health Care Management Organization Design and Behavior. Clifton Park, NY: Delmar Cengage Learning; 2012.

[34] Clark J, Armit K. Leadership competency for doctors: a framework. Leadersh Heal Serv. 2010; 23(2): 115-29. http://dx .doi .org/1 $0.1108 / 17511871011040706$

[35] Edwards N. Doctors and managers: building a new relationship. Clin Med. 2005; 5(6): 577-9. PMid: 16411354. http://dx.doi.org/1 $0.7861 /$ clinmedicine.5-6-577 